\title{
An airborne EM survey of a landfill that leaked
}

\author{
The British Geological Survey continues to highlight the need for, and environmental assessment \\ potential of, modern, multi-sensor airborne geophysical data in the UK. Here David Beamish, ${ }^{*}$ head of \\ airborne geophysics at the BGS, describes some results obtained from a detailed survey of a legacy \\ landfill.
}

Throughout central Scotland, the Lower and Middle Coal Measures have been worked for coal production. Numerous seams are present and extensive workings and voids can be a pervasive feature of the subsurface. Environmental regulations require a reassessment into the nature and possible impact of these workings when a site is considered for redevelopment. This study describes an airborne electromagnetic survey (AEM) carried out in 2004 in the vicinity of the Eastfield quarry, former landfill situated in West Lothian, Scotland. The landfill is situated on the former Polkemmet colliery site. The purpose of the survey was to investigate the capabilities of the technique in relation to environmental site assessments.

A number of airborne geophysical surveys have now been conducted in the UK using a fixed-wing system operated jointly by the British and Finnish Geological Surveys. The system provides magnetic, radiometric, and frequency domain electromagnetic (EM) survey measurements (Peart et al., 2001). Application of the AEM technique to landfill investigations is reported by Beamish (2003) and Beamish and Mattsson (2003). In addition to fixed-wing surveying, helicopter (towed-bird) survey configurations can also be undertaken. The survey bird usually acquires magnetic and electromagnetic data. The bird must be flown at very low altitude, typically $30 \mathrm{~m}$, in order to provide adequate signal-to-noise. The survey and data presented here provide, to the best of our knowledge, the first detailed environmental application of helicopter AEM surveying in the UK.

The study presents results obtained from a small-scale helicopter AEM survey of a closed waste disposal landfill. The landfill, occupying a former quarry, is situated among shallow, worked-out coal seams (pillar and stall workings) and was located over at least two mineshafts that occupied the quarry floor. The landfill was known to be leaking from an extensive borehole investigation that took place in the 1970s, when the landfill was active. Redevelopment issues and associated, proposed surface extraction of coals have renewed interest in the possible pollution threat of waste products. Of particular concern is the extent to which pollution has, potentially, transgressed a fault to the north and entered the area of proposed regeneration. The airborne survey data (EM and magnetic) were obtained using the six-frequency RESOLVE bird and a flight line spacing of $40 \mathrm{~m}$. The data have been subjected to $1 \mathrm{D}$ regularized inversion to enable a 3D conductivity model to be assessed.

The model clearly identifies the landfill as a source term of highly conductive materials but provides no geochemical discrimination. At conductivities that are a factor of $\sim 3$ above background, evidence is obtained for a variety of vertically compact, lateral migration pathways, largely below the base of the quarry. A limited amount of ground geophysical follow-up has provided a degree of confirmation of the airborne model.

\section{AEM survey}

The AEM survey was carried out using the six frequency $(0.4$ to $110 \mathrm{kHz})$ RESOLVE helicopter AEM system (Fugro Airborne Surveys) as part of a research project into the application of AEM in the UK environment. Magnetic data from the Caesium magnetometer mounted in the RESOLVE bird were also acquired. The nominal bird height above ground was $30 \mathrm{~m}$. The main survey lines, a total of $\sim 54$ line $\mathrm{km}$, including three tie-lines, are shown in Figure 1a.

The main survey area covers a $1 \times 1.5 \mathrm{~km}$ block taking in the target landfill and a regional fault to the north. Several issues relating to detailed towed-bird AEM data acquisition were revealed. Overflights above the local village were not permitted so that flight lines just to the south of the target were curtailed by climbs and veers. Although a N-S line separation of $20 \mathrm{~m}$ was specified, only a $40 \mathrm{~m}$ separation could be achieved using a relatively inexperienced pilot.

\section{Eastfield Quarry landfill}

Eastfield quarry worked a sandstone outcrop within the Lower Coal Measures to a depth of 31-32 $\mathrm{m}$. The quarry was located on former (early 19th century) colliery shafts. Two of these are known and another is suspected. Landfill operations began in the 1950s when the site was leased for domestic refuse. Industrial waste disposal began in 1963 and the type industrial wastes included paints, solvents, oils, sludges and treated cyanide, i.e. large volumes of liquid waste products. From 1972, the Deposit of Poisonous Waste Act allowed for greater control and since that date, $47,000 \mathrm{~m}^{3}$ of liquid waste $\left(33,500 \mathrm{~m}^{3}\right.$ containing oils) were deposited. A permanent liquid waste lagoon formed, perched above one of the 19th century shafts. A photograph of the operational landfill is shown in Figure 2. Input of solid waste ceased in 1979 and the landfill was covered and graded. The AEM survey took place some 24 years after closure. 

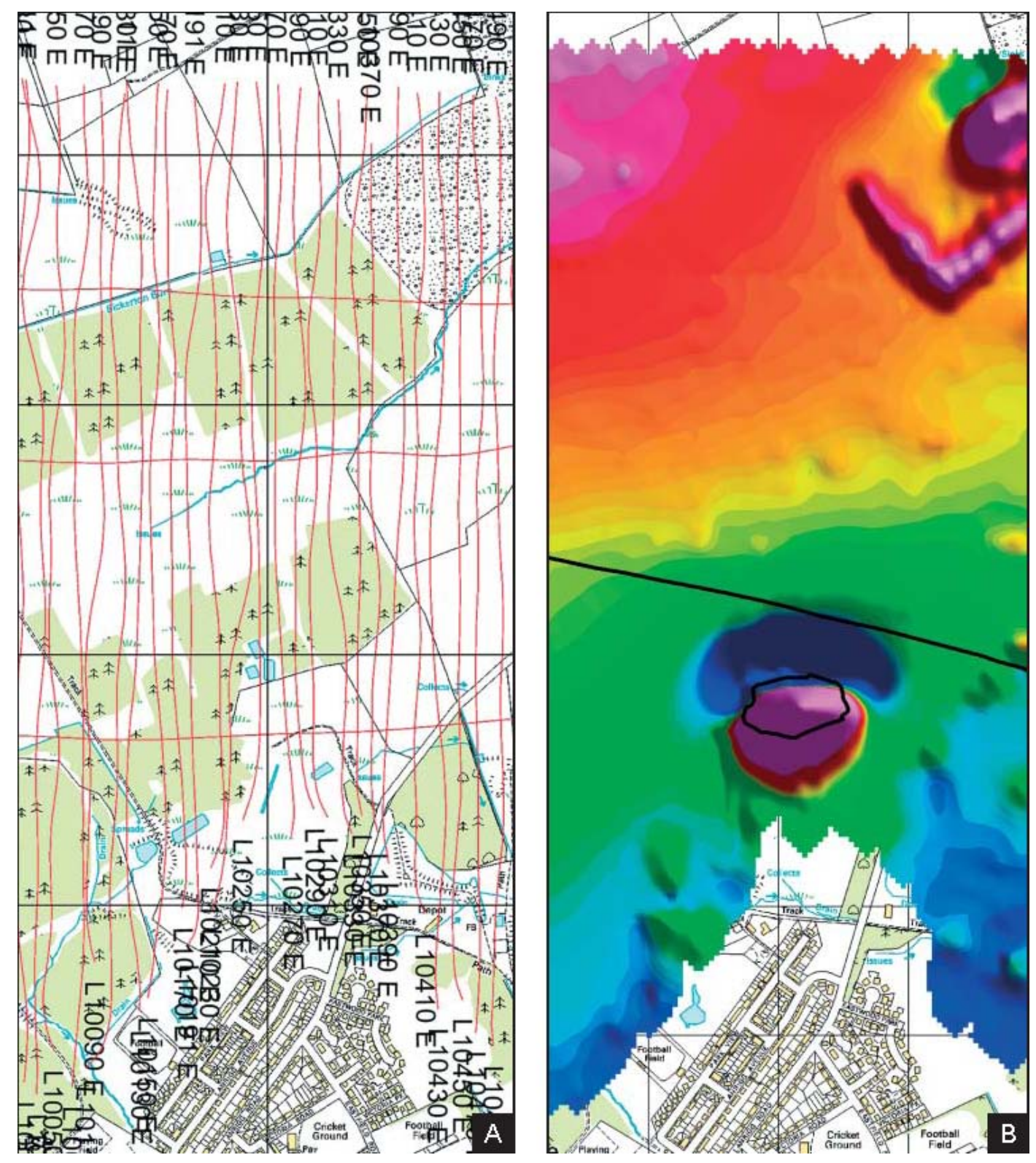

Figure 1 (a) Survey flight lines (red lines) on background OS 1:10k map (CCrown copyright. All rights reserved). Grid indicates $500 \mathrm{~m}$ intervals. (b) Total Magnetic Intensity. Surface trace of Polkemmet fault and former quarry outline are shown in black.

Historically the active landfill was the subject of a detailed BGS hydrogeological characterization research programme (Harrison et al., 1981). Eleven boreholes were drilled; three within the landfill. At that time (1974), aqueous wastes were found to have migrated through the shafts and into shallow worked coal seams surrounding the site. Oils and acidic leachates were found in fractures within the underlying sandstone and also $300 \mathrm{~m}$ down dip (west) within the highest worked seam (the Upper Drumgray seam $\sim 46 \mathrm{mbgl}$ ).

A large area to the north of the landfill is due for regeneration in an ambitious scheme to develop the former colliery site. Initial phases of the scheme involve surface extraction of coal and fireclay. The environmental/technical issues of redevelopment have renewed interest in the extent of possible migration of source materials. One of the main issues of concern is the possibility of any leachate migration northwards from the landfill and the degree of any transgression across the fault.

\section{Magnetic results}

The magnetic survey data, restricted to the main survey area, reveal two main anomalies as shown in Figure $1 \mathrm{~b}$. The main anomaly is a $1000 \mathrm{nT}$ dipolar perturbation associated with the landfill. This N-S oriented feature appears due to remnant magnetization within deposited ferrous materials. A further small anomaly (100 nT) appears in association with a long-term ( 25 years) burn area across the coal spoil heap (Polkemmet Bing No 3 ). A picture of the bing taken, from the south looking north is shown in Figure 3. The L-shaped small magnetic high 
on the southern, lower flanks of the bing corresponds to the zone of persistent burn. The magnetic data, although of scientific interest, have not been processed further.

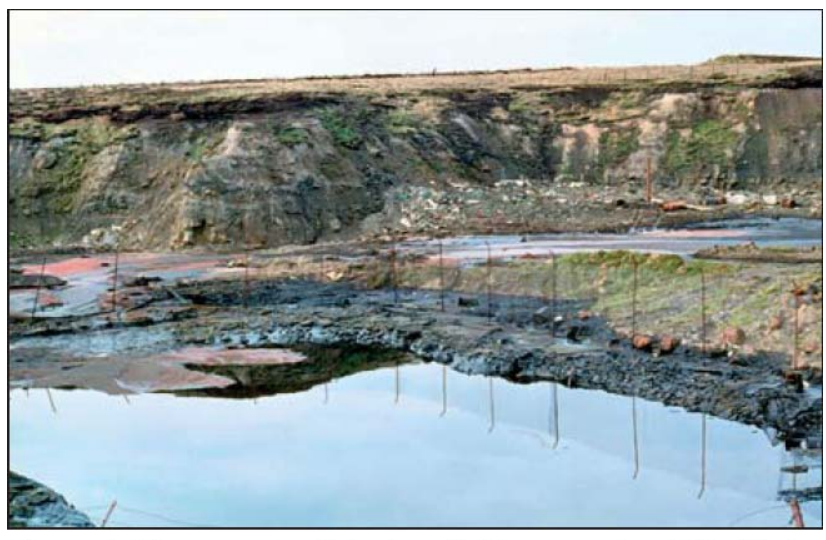

Figure 2 Photograph of the Eastfield quarry landfill, 1974.

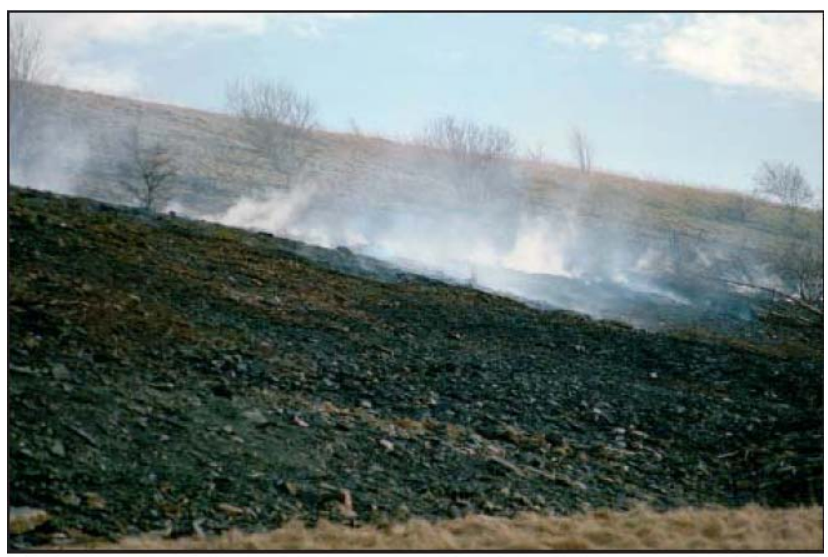

Figure 3 Photograph of Bing No 3 taken from the south looking NE, on the day of the survey.
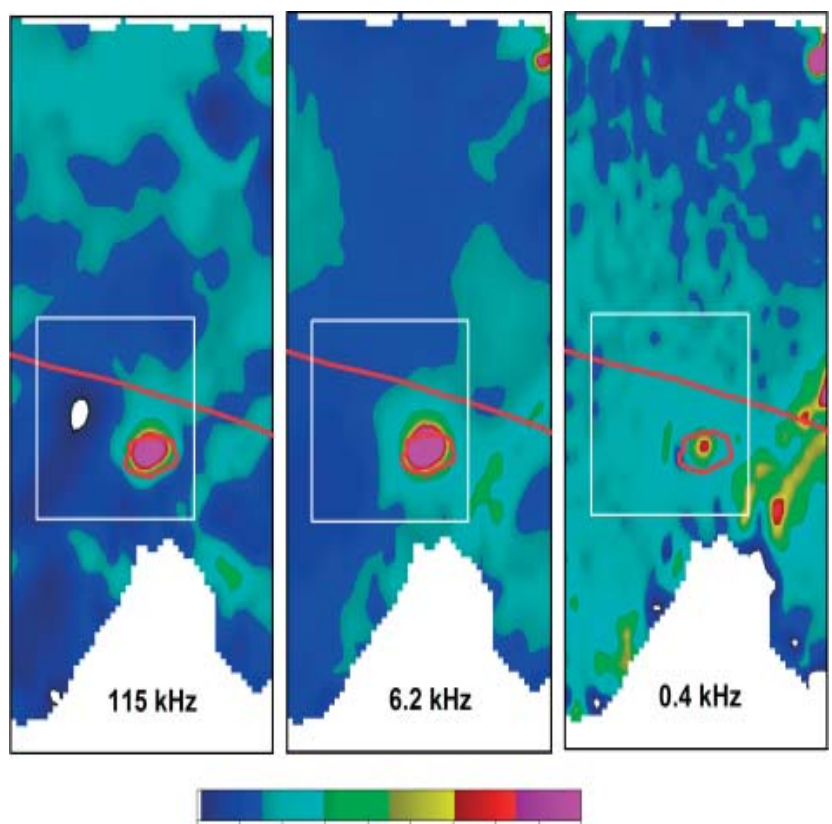

$\begin{array}{lllllllllll}5 & 10 & 15 & 20 & 25 & 30 & 35 & 40 & 45 & 50\end{array}$ Apparent Conductivity $(\mathrm{mS} / \mathrm{m})$
Figure 2 Photograph of the Eastfield quarry landfill, 1974.

Figure 3 Photograph of Bing No 3 taken from the south look-ing NE, on the day of the survey.

Figure 4 Half-space apparent conductivity distribution at fre-quencies of 115, 6.2, and $0.4 \mathrm{kHz}$. Surface trace of Polkemmet fault and former quarry outline are shown in red. Box defines a $600 \times 600 \mathrm{~m}$ detailed study area. 


\section{Electromagnetic/conductivity results}

The RESOLVE electromagnetic data comprise coupling ratios from five horizontal coplanar coil pairs (nominal frequencies of $400,1500,6200,25,000$, and $11,500 \mathrm{~Hz}$ ) together with a coaxial pair operating at $3300 \mathrm{~Hz}$. Sampling of all data is at $10 \mathrm{~Hz}$ providing data every $3.2 \mathrm{~m}$ along flight lines. These data can be used to provide a variety of half-space apparent conductivity maps together with approximate frequency-depth transform models.

The standard form of mapping is in terms of the half-space model derived from the coupling ratios at each frequency. The conductivity mapping information obtained by this type of procedure is shown in Figure 4 . The sequence is from high to low frequency (shallow to deep penetration depths) at frequencies of $115,000,6200$, and $400 \mathrm{~Hz}$. Centroid depths, meaning the depth of the 'centre-of-gravity' of the induced in-phase current system, have been calculated from the statistics across the main survey area. Mean values are $6.9 \mathrm{~m}(115,000 \mathrm{~Hz}), 14.5$ m (25,000 Hz), $27.5 \mathrm{~m} \mathrm{(6200} \mathrm{Hz),54} \mathrm{m} \mathrm{(1500} \mathrm{Hz),} \mathrm{and} 106 \mathrm{~m}(400 \mathrm{~Hz})$. The landfill shows a peak conductivity response at $6200 \mathrm{~Hz}$. Centroid depths within the conductive landfill area, at this frequency, range from about 13 to $20 \mathrm{~m}$.

The results shown in Figure 4 reveal that the conductivities of the Lower Coal Measure sequence range from about 5 to $20 \mathrm{mS} / \mathrm{m}$ (a factor of 4). The regional scale Polkemmet Fault shows no readily discernable conductivity expression. This is to be expected since, although the fault downthrows the solid geology by $\sim 100 \mathrm{~m}$ to the south, similar geological materials exist to the north and south.

With decreasing frequency, a NE-SW striking conductivity anomaly, to the east of the landfill, becomes increasingly apparent. The form of the anomaly, most pronounced at $400 \mathrm{~Hz}$, conforms to an 'M' shaped feature (high-low-high amplitude) orthogonal to strike. This is the classic response of a line-current (power line). The RESOLVE power-line monitor channel also tracks the overhead power line responsible for the anomaly. As indicated in the conductivity maps of Figure 4, the perturbation increases with decreasing frequency and has a large spatial influence on the models derived from the coupling ratios.

The above procedures, while useful, do not provide sufficient resolution or discrimination to fully address the technical issues posed by the landfill. In order to fully exploit the information provided by the data, it is necessary to undertake formal inversion of the full spectrum of data. At present, routine procedures for airborne data are limited to 1D assessments. These models may then be stitched together to allow a consideration of the conductivity distribution within a subsurface volume.

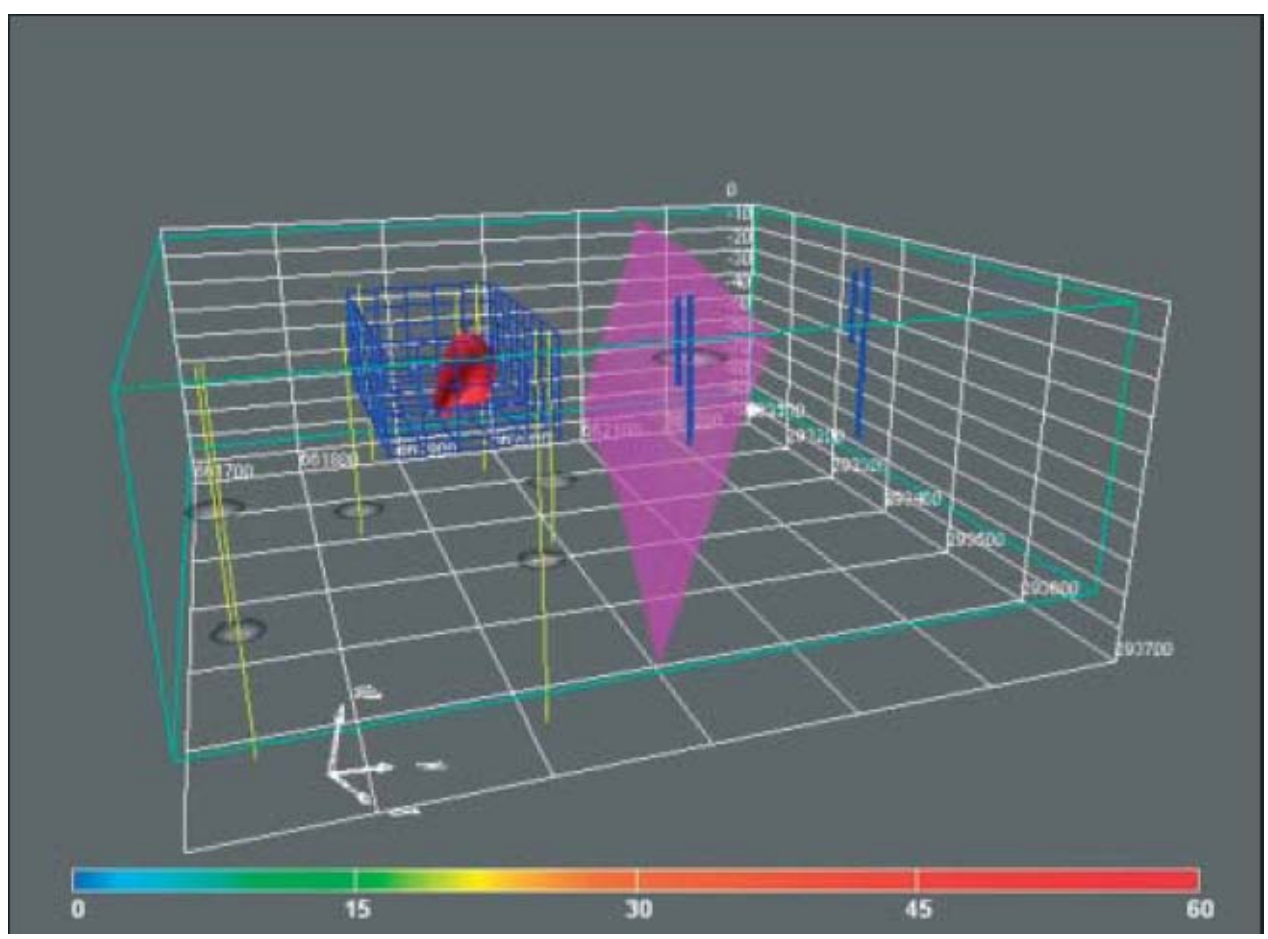

Figure 53 perspective view of conductivity model (colour scale bar in $\mathrm{mS} / \mathrm{m}$ ) within $600 \times 600 \times 100 \mathrm{~m}$ selected volume, looking east to west. V.E. x 2.5. $200 \mathrm{mS} / \mathrm{m}$ isovolume. Descriptions of other objects are in the text. 
Various forms of regularized (Occam) 1D inversion have been applied to the data. The results described here were obtained using the algorithm described by Zhang and Oldenburg (1999). The goal of the inversion is to find a model that reproduces the data and exhibits certain desired characteristics. The desired characteristic is a 1D conductivity model that has minimum structure in the vertical direction and, at the same time, is close to a reference model. The reference model used here is the best fitting half-space. It is acknowledged that the conductive landfill will also provide a) magnetic and b) three dimensional influences that are not taken into account in the modelling procedure.

While necessary limiting resolution in the vertical direction, such models are highly useful in mapping lateral changes within the subsurface volume. Using a realistic assignment of data errors (5\%) and a 25 layer model (extending to a depth of $100 \mathrm{~m}$ ), chi-squared misfits around the expectation of 12 are achieved except on one central line through the landfill zone. The resulting conductivity models have been incorporated into a 3D visualization program that allows conductivity isosurfaces and isovolumes to be realized. In order to provide a detailed assessment of the conductivity distribution associated with the landfill and in order to avoid the perturbation introduced by the power-line, a zone of $600 \times 600 \times 100 \mathrm{~m}$, outlined in Figure 4 is considered.

Figure 5 shows a conductivity isovolume of $200 \mathrm{mS} / \mathrm{m}$ across the selected volume in which additional elements have been incorporated into the visualization. The high value of $200 \mathrm{mS} / \mathrm{m}$ defines only highly conductive source materials associated with high levels of total dissolved solids (TDS); this material is clearly confined to a localized volume within the former landfill. The blue skeleton box, extending to $30 \mathrm{~m}$, outlines the extent of the quarry/landfill. Vertical yellow lines denote the locations and depths, below surface, of the bore-hole investigations carried out in the 1970s. Horizontal coloured discs denote water levels. The two sets of blue vertical lines denote modern investigation borehole locations to south and north of the fault. The dipping transparent feature indicates the Polkemmet fault. As the conductivity is further reduced, pathways containing lower levels of TDS are revealed. A lower conductivity of $35 \mathrm{mS} / \mathrm{m}$ provides a level that is $\times 2$ to $\times 3$ above background geological levels and hence is attributable to enhanced TDS from landfill source materials.

Figure 6 attempts to summarise the main attributes of the conductivity model. An isosurface of $35 \mathrm{mS} / \mathrm{m}$ is used. A confined area of conductive breakout appears at a depth of about $8 \mathrm{~m}$ to the north of the landfill. The major northward breakout occurs at depths $>30 \mathrm{~m}$ and a conductive tongue

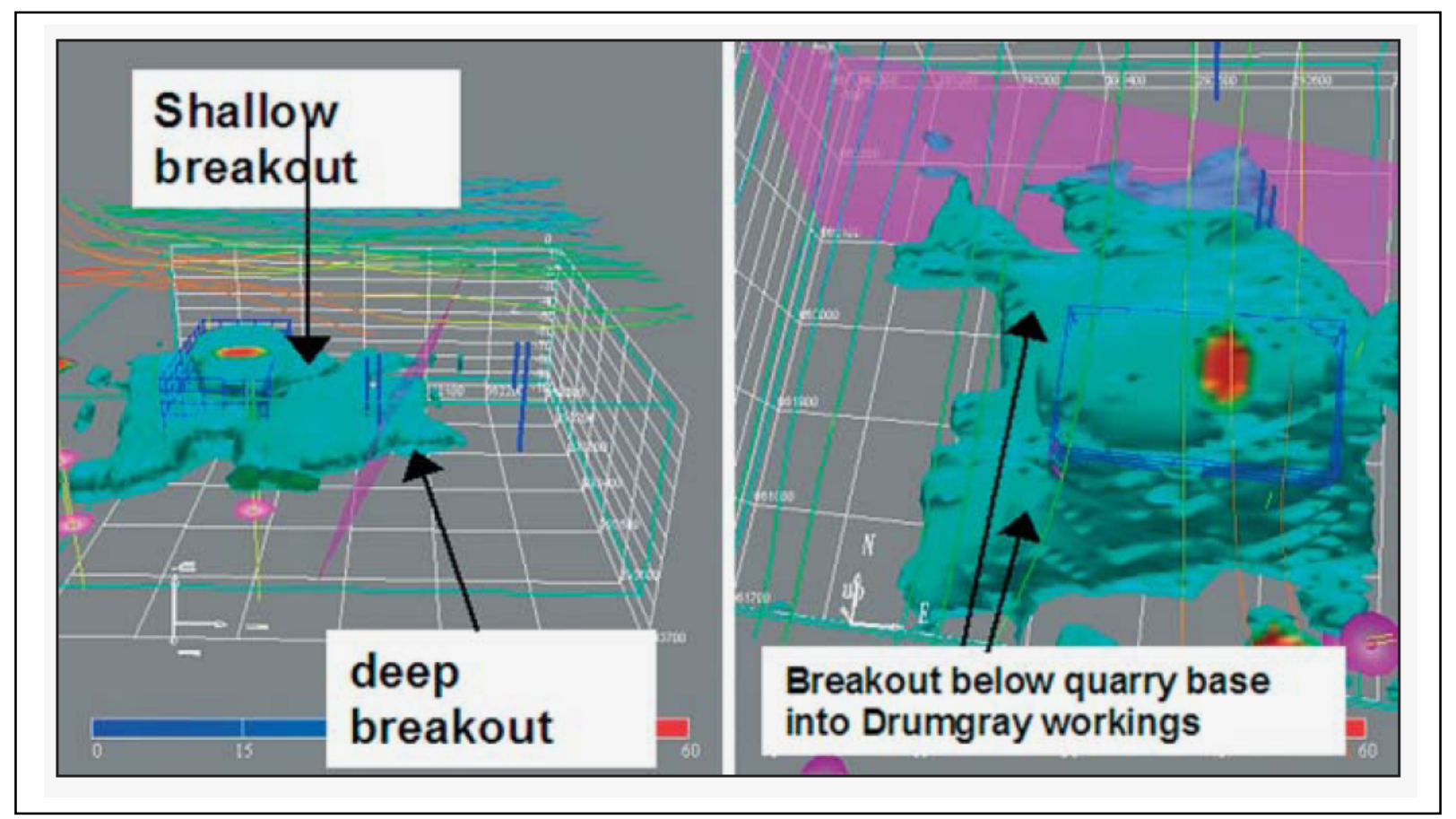

Figure 6 Two 3D perspective views of the same conductivity isovolume of $35 \mathrm{mS} / \mathrm{m}$. Uppermost lines are flight lines. Other details as previously. 
traverses the fault largely below the base of recent investigation boreholes. To the west and south-west, deep breakout appears to correlate with the location/depth of the worked Upper Drumgray seam. The feature appears consistent with the interpretations derived from the borehole investigations noted previously.

Since there is a lack of control information regarding the conductivities of geological formations at the site, it was considered prudent to carry out a limited ground geophysical assessment, to provide a degree of confirmation of the models obtained from the airborne survey.

\section{Ground geophysical follow-up}

As a follow-up to the airborne survey, a set of five Schlumberger vertical electric soundings (VES) were obtained across the survey area. Two soundings (02 and 05) are contained within the former quarry/landfill. Sounding 01 lies to the south of the Polkemmet fault and the remaining two soundings ( 03 and 04 ) form a geometrical cross to the north of the fault.

Figure 7 shows the one dimensional conductivity models obtained at all five sounding locations. Both depth and conductivity are shown using a logarithmic scale. The models shown with symbols were obtained using an Occam regularized inversion. This form of inversion procedure forces the profile to be smoothly varying and the resulting profile has 'minimum structure'. The results were obtained assuming all the data had errors of $5 \%$ and the data were fitted to an rms error of $1 \%$.

The three soundings $(01,03$, and 04$)$ represent background profiles for the Lower Coal Measure sequence. The two soundings ( 03 and 04 ) to the north of the Polkemmet Fault are mutually consistent and provide a small variation of between 4 and $8 \mathrm{mS} / \mathrm{m}$ over the depth range shown. Sounding 01 to the south of the fault displays persistently higher conductivities although the overall form of all three profiles is similar. The two soundings within the quarry/landfill area (02 and 05$)$ display consistently higher values than background particularly at depths $>1$ $\mathrm{m}$. Both profiles ramp to high values in the depth range 15 to $20 \mathrm{~m}$. The limited lateral extent of these soundings means that the depth of investigation is more restricted than soundings 01,03 , and 04 . A conventional layered conductivity for sounding 05 (black line) is also shown for comparison. This model achieves a misfit error of $2.1 \%$ and indicates a high conductivity zone $(95 \mathrm{mS} / \mathrm{m})$ between depths of 8 and $41 \mathrm{~m}$. Equivalence studies indicate that the base of the conductive zone is not well resolved, however.

Overall the ground investigations have provided a broad degree of confirmation of the airborne model. Background conductivities within the Lower Coal Measure sequence appear low and, although we only have three such soundings, we could anticipate non-geological influences being detected at conductivity levels in excess of, say, $15 \mathrm{mS} / \mathrm{m}$. Elevated conductivities, at all depths, are confirmed within the quarry/landfill area. Very high conductivities appear at depths $>8 \mathrm{~m}$ however the base of the conductive zone is not well resolved. One estimate of $40 \mathrm{~m}$ is consistent with the form of the model obtained from the airborne data.

\section{Conclusions}

The Eastfield helicopter AEM survey probably represents the first UK application of such technology to a detailed environmental site assessment. The survey has highlighted a number of issues related to data acquisition at the site investigation scale. These include the difficulties of achieving adequate flight line coverage and, also, the significant interference from a single overhead power line.

The magnetic survey data reveal two main anomalies across the site. The main anomaly is a $1000 \mathrm{nT}$ dipolar perturbation associated with the landfill. This N-S oriented feature appears due to remnant magnetization within deposited ferrous materials. A further small anomaly (100 nT) appears in association with a long-term burn area across the coal spoil heap (Polkemmet Bing No 3).

In order to extract pertinent information from the six frequency AEM data it was necessary to perform 1D inversion. The resulting conductivity model appears to resolve conductive materials associated with a landfill that was known to be leaking some 30 years before the survey. A confined area of conductive breakout appears at a depth of about $8 \mathrm{~m}$ to the north of the landfill. The major northward breakout occurs at depths $>30 \mathrm{~m}$ and a conductive tongue traverses the fault largely below the base of recent investigation boreholes. To the west and southwest, deep breakout appears to correlate with the location/depth of the worked Upper Drumgray seam. The 


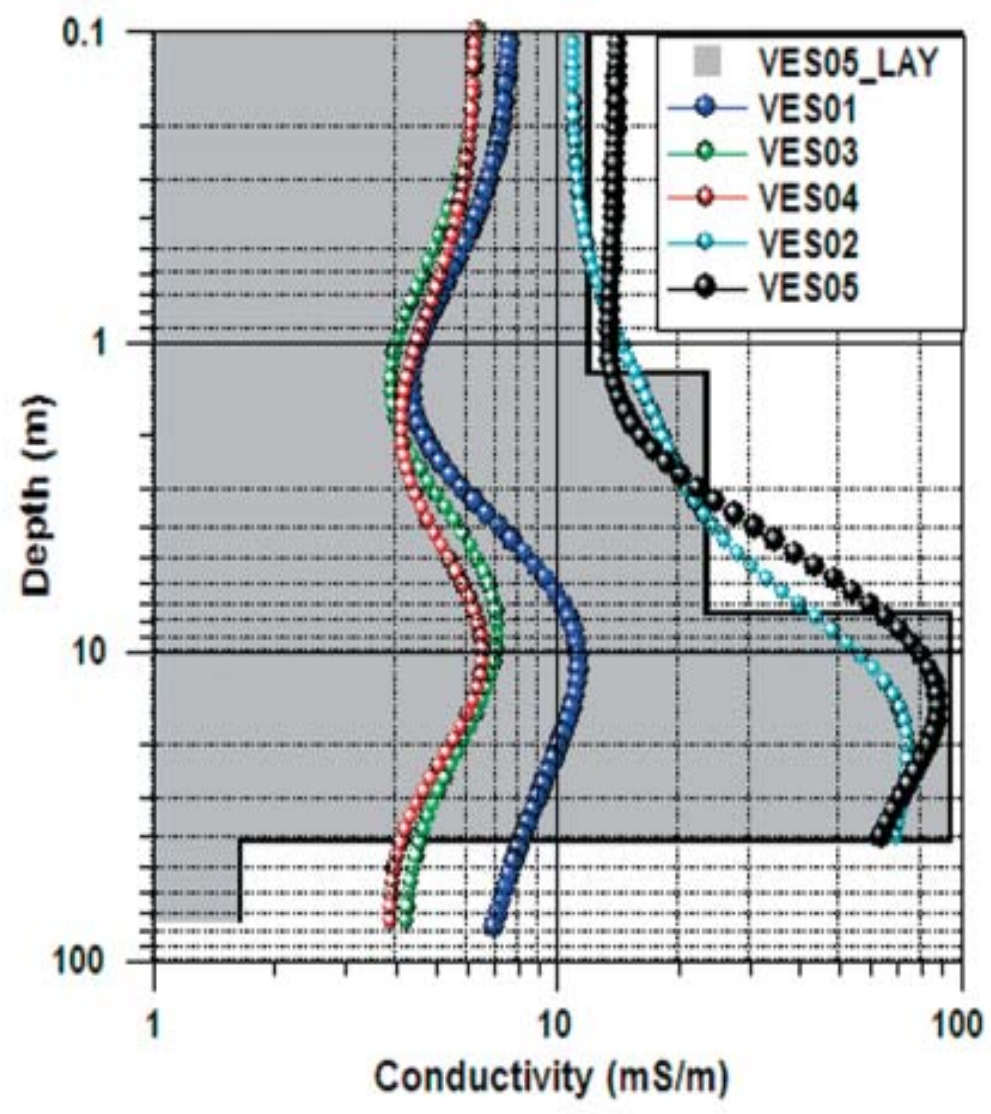

Figure 7 Conductivity models obtained by five VES sound-ings. Soundings with symbols denote smooth model inversions. The single layered profile (with infill) obtained on the quarry site (VESO5_LAY) is shown for comparison.

A degree of broad confirmation of the airborne conductivity model has been established by ground geophysical follow-up. Background conductivities within the Lower Coal Measure sequence appear low and we could anticipate non-geological influences being detected at conductivity levels in excess of, say, $15 \mathrm{mS} / \mathrm{m}$. The inferences on breakout have been made using an isovolume conductivity level of $35 \mathrm{mS} / \mathrm{m}$. Elevated conductivities, at all depths, are confirmed within the quarry/landfill area.

Due to the low conductivity of the Coal Measures, only the conductive component of leachate migration is resolved. According to Harrison et al. (1981), the main potential pollutants are heavy metals, acids, and organic matter (principally oils). Biological degradation within the mine workings is unlikely to be significant since conditions for efficient aerobic breakdown are lacking. Oils, perhaps accounting for only $10 \%$ of the liquid wastes, should remain resistive. The cause of the conductive component is therefore likely to derive from the highly acidic and mobile sulphate component found in high concentrations (typically $>1000 \mathrm{mg} / \mathrm{l}$ ) in the pore waters extracted by the borehole study in the 1970s. The precise geochemical nature of the conductive breakout remains speculative until further modern control information can be provided.

\section{Acknowledgements}

The assistance of Greg Paleolog and Mike Cain (Project Geophysicist) of Fugro Airborne Surveys is much appreciated. Mike Raines and Rhys Cooper of the BGS conducted the ground geophysical surveys. 


\section{References}

Beamish, D. [2003] Characterising landfills from the air. First Break, 21, 10, 67-72.

Beamish, D. and Mattsson, A. [2003] Time-lapse airborne EM surveys across a municipal landfill. J. Environmental \& Engineering Geophysics, 8, 157-165.

Harrison, I.B., Parker, A., and Williams, G.M. [1981] Investigation of the landfill at Eastfield Quarry, Fauldhouse, Westlothian, Scotland. Institute of Geological Sciences Report 81/13.

Peart, R.J., Cuss.R.J., Beamish, D., and Jones, D.G. [2003] Locating and mapping potential environmental hazards in the UK with high resolution airborne geophysics. Geoscientist, 13, 7, 4-7.

Zhang, Z. and Oldenburg, D.W. [1999] Simultaneous reconstruction of 1D susceptibility and conductivity from electromagnetic data. Geophysics, 64, 33-47.

Article from First Break , 2005, 23, 55-60. 